\title{
Transformation of corporate governance models in investment funds
}

\author{
Aleksandr Metzger* \\ CJSC «Management Company», Tramvainyi Ave, 15, 620041 Yekaterinburg, Russian Federation
}

\begin{abstract}
The article is devoted to the phenomenon of corporate governance in investment funds, as one of the key elements ensuring the effective functioning of this institution of financial intermediation. A narrow and formal understanding of the term "corporate governance" in mutual funds is reduced to the relationship between owners and leaders of the management companies. This problem is devoid of practical sense in the context of highly concentrated ownership in these companies. The author proposes an expanded interpretation of corporate governance based on considering an investment fund as an "investment corporation", in which the participants are various categories of investors, fund management, as well as a number of other participants and stakeholders, depending on the nature of the investment process. Considering corporate governance as a system of control and management in Russian investment funds, the author comes to a number of conclusions. The current model considers the protection of the interests of fund investors from the opportunism of managers as a priority and meets the specifics of a certain market segment. The same model, but under different conditions, becomes redundant or even destructive. The analysis of the specifics of the activities of the investment funds for qualified investors makes it possible to formulate adequate changes in the corporate governance model. These include: 1) the transition to a model of coordinating the interests of the investors (controlling and minority), as well as other participants in the investment process, 2) reducing external regulation and moving to internal mechanisms for assessing and making decisions, taking into account the qualifications of the participants themselves, 3) limiting or compensation for the excessive influence of the controlling investor with a concentrated structure of investors.
\end{abstract}

\section{Introduction}

The investment fund industry is currently one of the most important segments of the financial market in almost any economically developed country. Like other institutions of financial intermediation (commercial banks, insurance companies, pension funds), this industry ensures, on the one hand, the satisfaction of the interests of various categories of investors, and on the other hand, transforms financial resources into capital for the real sector of the economy. Despite the relevance of such tasks for modern Russia, the

\footnotetext{
* Corresponding author: metzger@azkapital.ru
} 
development of the investment funds lags far behind the commercial banks dominating in the Russian financial system. The volume of funds accumulated in investment funds has recently slightly exceeded the same amount in pension funds, but rather "thanks" to the extremely unsuccessful state policy towards the latter. In other words, it can be stated that Russian investment funds are unable to unleash their potential and become an attractive instrument for both institutional and ordinary investors.

The overwhelming part of the numerous theoretical studies devoted to the problems of investment funds, for the most part, consider only partial fragmentary aspects of activities, such as the formation of an optimal portfolio of securities, the peculiarities of investment strategies in local markets, etc. At the same time, there are practically no analytical studies devoted to the processes of interaction between the participants in the investment process in funds (investors, managers, stakeholders). Out of the field of view of the researchers are the differences of interests of certain categories of investors, the ability of investment funds to meet these interests. The efforts of the regulator represented by the Bank of Russia and the professional community represented by NAUFOR (National Association of Stock Market Participants) look much more systemic. The system of regulatory documents, standards and rules developed and being improved by them, updating the best practices of behavior of market participants, is aimed at ensuring the stability of both an individual investment fund and this industry as a whole. If we consider an investment fund as a kind of "investment corporation", then all of the above is a model of corporate governance - an integral combination of decision-making and coordination mechanisms, taking into account the interests of both the main participants of the corporation and the stakeholders. The analysis of this model shows that today its priority is to protect fund investors from the opportunistic behavior of the management company (fund managers).

Without denying the existence of this task as applied to investment funds, it should be noted that its relevance in certain market segments has decreased, up to its complete disappearance. As a consequence, the management mechanisms aimed at protecting the interests of investors, at least become excessively costly, i.e. start to work against the interests of investors.

In other cases, it is not so much to protect the interests of investors as to protect them from their excessive influence on the decision-making process (for example, with a concentrated structure of the investors). This influence, amplified through the mechanisms of control over fund management, becomes destructive - it destroys corporate value, formed not only due to the contribution of investors, but also due to the contribution of other participants and stakeholders.

As a result, a unified and seemingly consistent system of control and management decision-making in investment funds leads to serious distortions under certain combinations of conditions and formats for the functioning of the funds. These distortions are manifested in excessive actions (expenses) when solving an urgent problem, or even in actions (costs) devoid of meaning, since they are aimed at achieving a false and irrelevant goal under the given conditions.

Thus, an attempt is made in the work to differentiate the conditions for the functioning of investment funds and to offer models of control and management decision-making (models of corporate governance) adequate to these conditions. Along with a systematic analysis of the conditions for the implementation of the activities of the investment funds, the work uses the methodology for the formation and substantiation of corporate governance models developed for classical entrepreneurial corporations.

\section{Materials and methods}

In the most general form, corporate governance is a set of mechanisms for making and 
controlling managerial decisions, which reduces the negative effects of the association of various participants and maximizes the positive effects of this association for them. For all the lightness of this definition ("for all good, against all bad"), it allows you to operate with the real interests of various participants, taking into account which ensures not only the stability of the "corporation", but also its development. In this case, it becomes extremely important to single out significant participants, as well as to identify the basic problem typical for this composition of participants. The theory and practice of corporate governance in "entrepreneurial" corporations provides an extensive methodological basis that, with some adaptation, can be used in the case of investment funds.

The issues of corporate governance in investment funds (fund governance) have long been the subject of scientific and practical research abroad [1-7]. Similar issues are considered in relation to the industry of Russian investment funds. However, the interpretation of this concept is only one of the concepts of corporate governance in entrepreneurial corporations (resolution of the conflict between the owners and managers). Moreover, the lack of taking into account the specifics of the organization and functioning of the institution of an investment fund leads to additional costs, but does not allow minimizing the specific manifestations of the same opportunism of managers (fund management companies).

For example, in accordance with the Federal Law "On Investment Funds" [8], it is possible to create either a joint stock (JIF) or a mutual investment fund (MIF). If in the first case we are talking about a joint-stock company, then a mutual investment fund is "a separate property complex consisting of property transferred to the trust management of a management company by the founder(s) of trust management ... A mutual investment fund is not a legal entity."

In accordance with the Civil Code of the Russian Federation [9], corporate legal entities (corporations) are legal entities whose founders (participants) have the right to participate (being members) in them and form their supreme body. Thus, the interpretation of a corporation as a business entity is quite appropriate in the case of JIF and, for example, is easily translated into corporate governance bodies familiar to entrepreneurial corporations: the general meeting of shareholders (investors), the board of directors. The role of the management company is also quite understandable - it performs the functions of fund management.

A completely different situation in the case of a mutual fund - the lack of legal entity status formally excludes this fund from the number of "corporations"! However, corporate governance needs to be implemented and the answer is easy to find - within the framework of the fund's management company, which can only be a business entity, i.e. is a "corporation".

The further logic is clear - it is on this corporation that the entire arsenal of mechanisms and practices of corporate governance is projected. The formal spread of effective practices to an object identical in its legal status leads to the absence of the expected result or a negative result, expressed in excess costs and restrictions, which do not lead to an increase in efficiency (the effect of "cargo cult"). Let us explain this statement. Allocation of protection of the interests of owners as a priority goal of corporate governance means that they are understood not as the fund's investors, but as the owners of the management company. It is for them that corporate governance bodies are formed, and corporate governance standards are developed. However, in the context of a super concentrated ownership structure of Russian management companies (the vast majority of them have a single beneficiary), the activities of all corporate governance bodies provide only formal, but costly compliance with the rules and regulations borrowed from the relevant practice of entrepreneurial corporations $[10,11]$.

The interests of other participants in the process of creation and functioning of 
investment funds, including investors, is, if not ignored, then considered by this interpretation in passing, indirectly, in the context of the "clients" of the management company.

Nevertheless, it can be argued that in the industry of Russian investment funds, a fairly stable model of real corporate governance has developed over the past two decades, although not without a number of restrictions. In contrast to the formal interpretation of corporate governance, in this case, the focus is not on the insignificant problem along the "management - owners of the management company" axis, but on the real problem of relationships along the "investors - management (management company) of the investment fund" axis. Quite rightly, this problem is identified as the "principal - agent" problem [12, 13], and mechanisms for accounting and protecting the interests of principals are being built in this direction, ie. fund investors. Why has this system of quite effective mechanisms that allow solving the "agency problem" not officially received the status of "corporate governance in investment funds"? It can be assumed that the reason is the fear of going beyond the narrow understanding of corporate governance as the relationship in a corporation between its owners and management. Since the vast majority of Russian investment funds are created in the form of mutual funds (not corporations!), and their investors enter into a trust management agreement (i.e., they are not the owners of the fund!), the whole range of issues related to the interests of investors and other interested parties can be called whatever you like, but not corporate governance!

However, the task of this work does not include the desire to restore terminological justice and call it as a corporate governance, what looks like this management solves the problems of this management and uses the methodology of this management. In our opinion, it is much more important to assess the current model of regulation and control in investment funds ("investment corporations") based on the theory and practice of corporate governance in "entrepreneurial corporations".

As noted earlier, at present, through the efforts of the regulator (the Bank of Russia) and the professional community, an integral system of mechanisms for monitoring and regulating the activities of investment funds has developed. The most significant elements of this system are briefly discussed below.

1. Organizations that make up the so-called "infrastructure of the fund", which, in addition to the management company itself, includes a mandatory specialized depository. In some cases, the infrastructure of the fund is supplemented by an auditor (funds for unqualified investors), a registrar (if the register of shareholders is not maintained by a specialized depository), and an independent appraiser (to assess the assets of the fund for which there is no recognized market quotation). A special role among these organizations is assigned to a specialized depository, which provides not only storage of the fund's property, but also control of the management company for compliance with legislation and in the interests of the fund's investors.

2. Normative documents of the Bank of Russia and self-regulatory organizations of market participants, which regulate the activities of management companies or set guidelines for the development of internal regulations of companies. The most significant areas of regulation include as follows:

- control of requirements for the composition and structure of fund assets;

- $\quad$ risk management of the management company;

- compliance of employees of the management company with qualification requirements and requirements for business reputation;

- control over the business reputation and financial position of the owners of the management company;

- conflict of interests of the management company and its employees in relation to the fund's investors. 
3. Special bodies of management and control of the investment fund. These bodies include the general meeting of the shareholders (investors) and the investment committee. In accordance with the current legislation, the general meeting of the shareholders is a mandatory element in closed mutual funds, and the competence of the meeting may include a wide list of significant issues, decisions on which are mandatory for the management company, up to the change of the management company! In turn, an investment committee can be created in investment funds for qualified investors. The powers of this committee, formulated in the Fund's Rules, allow almost complete control over the activities of the management company through the introduction of a permitting procedure for its transactions.

Even a simple listing and brief description of the elements of the system for monitoring and managing the activities of investment funds leaves no doubt about the general focus protecting the interests of investors from the opportunism of the management company. This conclusion is also confirmed by the introduction into the practice of regulating the investment fund industry of fiduciary responsibility - an attributive element of Anglo-Saxon law and an outsider (market) model of corporate governance. For example, the rules related to fiduciary responsibility for a management company are already spelled out in the Federal Law "On Investment Funds". According to him, the Bank of Russia may order the management company to compensate the client for real damage if it was received due to the fact that the management company did not show due diligence in the interests of the founder of the management.

\section{Results and discussion}

The evidence and justification of the existing model of "informal" corporate governance does not deny its further development and transformation. This hypothesis is confirmed by the multivariance of the corporate governance model in entrepreneurial corporations. Recall that in this case, theory, and most importantly, practice, distinguish two so-called "basic models" of corporate governance: the already mentioned outsider and insider (stakeholder) models. The dividing line between these models runs along the line, which is set by such parameters as the composition and characteristics of significant participants in the corporation, as well as the key conflict (problem), the resolution of which (solution of which) ensures the sustainable development of the corporation. The correct diagnosis of one version of the model or another largely determines the list of control mechanisms internal and external institutions, regulatory practices, etc.

For example, the outsider model is characterized by an attributive conflict between ordinary corporation owners and professional management. Dispersed ownership structure, lack of professional competencies among investors, all this determines the priority of the external mechanisms for control and conflict resolution. These mechanisms include, for example, a simple assessment of the effectiveness of management through market indicators, free entry and exit of owners ("voting with their feet"), fiduciary responsibility of management.

On the contrary, the stakeholder model is characterized by a more complex composition of significant corporation participants and stakeholders, as well as a concentrated ownership structure. Accordingly, the basic problem is the coordination of the interests of the participants and stakeholders of the corporation, as a key factor in its sustainable development [14-16]. The set of mechanisms that ensure the solution of the problem naturally changes - first of all, these are internal mechanisms of control and coordination, implemented through the construction of an internal "hierarchy" of management bodies, procedures for their interaction, evaluation of results, and decision-making. Note that building a largely unique "hierarchy" for each corporation is associated with significant 
internal costs, but ensures the functioning of the corporation in a complex institutional environment [17] or the formation of a more complex result, in the form of the so-called "corporate value".

We can now assess the feasibility of applying similar models to the investment fund industry. The task is greatly simplified if we take into account the attributive property of an investment fund as an institution of financial intermediation - the reflection (adequacy) of the nature of liabilities (fund investors) to the characteristics of its assets (target investment market). In this regard, Russian regulatory practice (as in most developed countries) differentiates investment funds as follows [18]:

- funds for unqualified investors, for which target markets (financial instruments or real estate) are limited to markets with high information efficiency and liquidity;

- funds for qualified investors, on the other hand, allow investments in poorly efficient and illiquid real estate and financial assets markets (venture capital fund or private equity format), form complex combinations of assets and liabilities (hedge fund format), and even implement entrepreneurial projects (combined fund format).

Analysis of the real Russian practice of the formation and functioning of investment funds allows us to make a number of important comments for the analysis.

The first point concerns the structure of the fund's investors. Almost all funds targeted at unqualified investors have a dispersed structure (the so-called "retail funds"). It can be assumed that these funds are not of interest to large investors. The latter, due to the lack of control mechanisms in this case, and, moreover, pressure on the management company (for example, the general meeting of investors and the investment committee) in order to implement decisions that ensure a profitable transfer of the fund's assets. In addition, the target asset market for these funds (efficient and liquid) significantly reduces the opportunities for transfer pricing transactions. In contrast, qualified investor funds tend to have a concentrated investor structure. The controlling, "anchor" investor gets the opportunity to control the management company through the management bodies [19], and the weakly efficient asset market allows using this opportunity in his own interests.

The second remark characterizes the initiator of the fund creation and further reinforces the situation caused by the structure of the investors. The fact is that the real initiative to create an investment fund is only in theory always the prerogative of the management company. In Russian practice, this option is usually common among "retail" funds, and created in the form of open, interval, and recently in the form of exchange-traded funds. A completely different picture is typical for funds for qualified investors. It can be argued that almost all funds for qualified investors, or in any case created in the form of a closed-end fund, are created at the initiative of the future controlling investor, and the management company is involved to ensure the administration of the fund - formal compliance with the necessary procedures, thereby formalizing the will and interests of the controlling investor

Thus, the whole variety of investment funds is not homogeneous from the point of view of corporate governance issues and objectively there are prerequisites for the formation of not one, but at least two basic models (Table 1).

Table 1. The main approaches to corporate governance and the corresponding basic approaches to corporate governance in investment funds

Outsider (market) model Insider (stakeholder) model

\section{Corporate governance}

a system of accountability, control and motivation of managers, ensuring that the interests of the fund's investors are met. a process by which a balance of interests is established, both of the fund's investors and other participants (subjects) of the investment process. 
Continuation of Table 1. The main approaches to corporate governance and the corresponding basic approaches to corporate governance in investment funds

\section{The main problem of corporate governance}

violation of investors' interests by fund formation of a stable and effective managers, as one of the options for system of interaction between manifesting an agency problem. participants, with different, often opposite interests.

\section{Limits of applicability}

The fund's investments are carried out in $\quad$ The fund's investments are carried out efficient liquid markets, and its formation in poorly efficient and non-liquid takes place at the expense of ordinary markets, which requires attracting funds unqualified investors. The dispersed from qualified investors and/or $\begin{array}{ll}\text { structure of the investors prevails. } & \text { involving other groups of stakeholders }\end{array}$ in the investment process. In Russia, as a rule, there is a concentrated structure of the investors.

\begin{tabular}{l|l}
\hline \multicolumn{3}{c}{ Nature of corporate governance mechanisms } \\
\hline $\begin{array}{l}\text { Market - based on the free receipt of } \\
\text { objective information and the }\end{array}$ & $\begin{array}{l}\text { Hierarchical - based on the coordinated } \\
\text { exchange of information between the } \\
\text { implementation of market transactions } \\
\text { participants and its assessment in } \\
\text { with minimal costs }\end{array}$ \\
$\begin{array}{l}\text { accordance with internal regulations and } \\
\text { procedures. }\end{array}$ \\
\hline
\end{tabular}

The scale of the potential distribution of the considered models can be estimated in Figure 2.

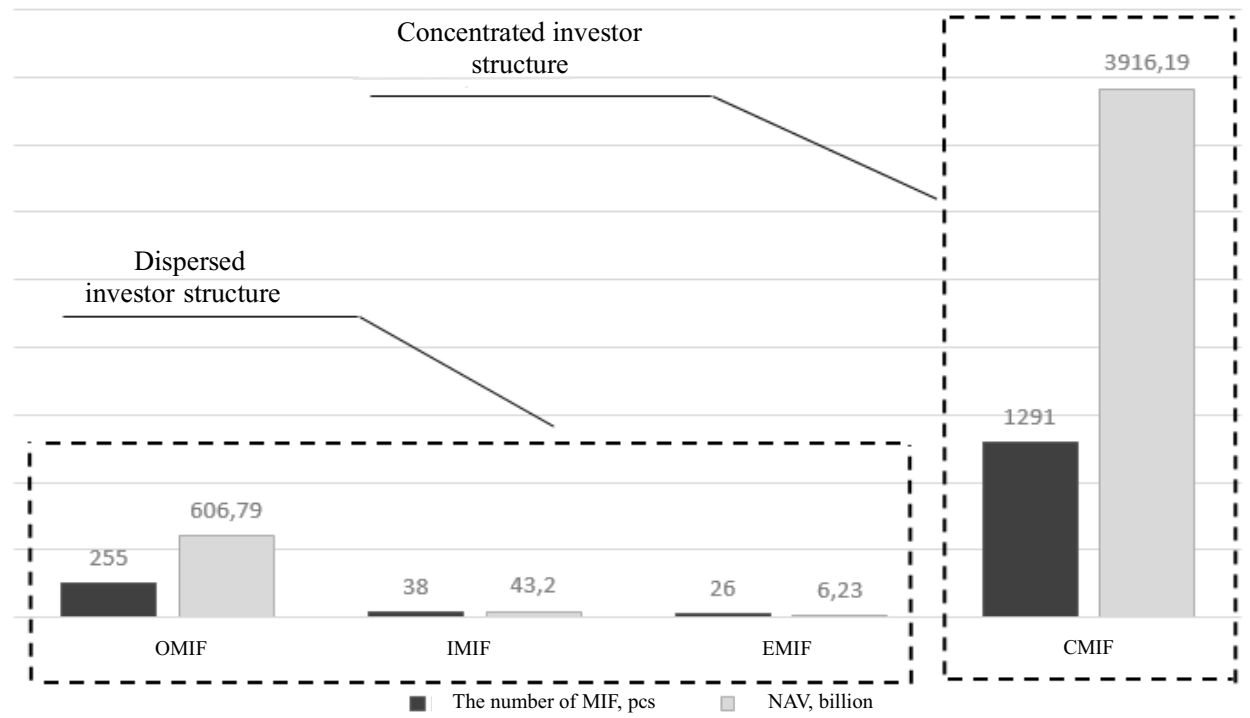

Fig. 1. The number of Russian open (OMIF), interval (IMIF), exchange-traded (EMIF) and closed (CMIF) mutual investment funds and the net asset value (NAV) corresponding to these funds [26,27]

As we can see, the validity of the outsider or market model remains only for open, interval and exchange-traded funds. The absence of large, controlling investors, characteristic of these types, highlights the classic problem of controlling management companies in the interests of ordinary unqualified investors. As noted above, it is this 
ideology that is embedded in the existing system of control over the activities of investment funds.

The only but rather important flaw of the existing model for this segment of funds is the lack of control over the management style of investment portfolios of funds. The fact is that the dominant (at least in Russian practice) active approach to management, that is, the search for undervalued and overvalued assets and the corresponding restructuring of the portfolio in liquid markets, including exchange markets, is recognized in world practice not only as ineffective, but also one of the most dangerous forms of opportunism of managers of management companies [20-23]. This is the reason for the cardinal shift of the global investment fund industry towards passive management strategies, including in the form of index funds and ETFs (exchange-traded fund, an index fund, whose shares are traded on the stock exchange). A gradual transition in this direction is also observed in Russia, where exchange-traded funds are analogous to ETFs.

The introduction into widespread practice of forms of passive investment based on a wide diversification of assets is most in the interests of ordinary inexperienced investors and from the point of view of corporate governance is no less important than control of the composition and structure of assets, transactions and business reputation. Another thing is that, in this case, priority should be given not to tough administrative pressure from the regulator. More justified is the introduction of the obligation to disclose the composition and level of total costs of the fund. It is on this characteristic, and not on the historical profitability of the fund, that ordinary investors' attention should be shifted when choosing a fund. It can be assumed that the management companies placed in these conditions of competition will be forced not only to reduce their remuneration levels, but also to abandon the costly but ineffective style of asset management.

In this case, the already mentioned exchange-traded funds, in which the threat of the emergence of an agency problem is practically excluded, are a kind of target reference point. Therefore, it seems somewhat redundant to extend the entire spectrum of control mechanisms to management companies focused on the management of exchange-traded funds.

The analysis shows that the current model of regulation is quite adequate to the systemic conditions for the functioning of investment funds focused on unqualified investors and on liquid, highly efficient markets. However, as has already been shown (see Figure 1), a much larger volume of funds operates under completely different conditions. Weak information efficiency of markets, a significantly larger range of participants and a more complex combination of their interests, all this makes it difficult to assess the "correctness" of the decisions made. The situation with the private equity fund can be cited as an illustration. In this case, we are already dealing not with an abstract investment portfolio formed on the exchange market, but with the investments in a specific enterprise with a clearly expressed and multidimensional subjectivity (managers of the recipient enterprise, its staff, local authorities, etc.). What is the algorithm for preventing or overcoming the conflicts of interest? Among which subjects? Neither general market regulation nor the markets themselves can answer these and other questions. Moreover, the preservation of priority for external formal mechanisms, or the hope for internal control mechanisms (for example, a meeting of investors and an investment committee), but in the context of a concentrated structure of investors not only does not contribute to the growth of corporate value, but also works in the opposite direction - to destroy it!

Overcoming the current situation ("two specific segments of the investment fund market - one regulation model") seems to be in the direction of deeper changes in the regulation of funds focused on inefficient markets, ensuring the formation of unique objects and investment schemes, and therefore involving subjects (groups participants) with different, often diverse interests and expectations. The priority in this case is the development of the 
internal mechanisms of control and motivation. On the one hand, legal administration is difficult in low-efficient markets, and on the other hand, the competence of investors is quite sufficient to both evaluate and even implement internal corporate control procedures. Examples are boards of directors, supervisory boards and investment committees set up in funds for the qualified investors. The search and implementation of best management practices, the development of codes and standards, taking into account the specifics of a particular fund - this is the direction in which the industry of these investment funds is advancing in developed countries [7,24].

Of course, the concentrated structure of the investors, characteristic of the same category of funds, presents a certain problem. However, the very awareness of this problem allows us to suggest possible solutions to the problem. This can be an analogue of limited partnerships, in which the securing of special rights to manage the fund by the controlling investor is inevitably accompanied by the acceptance of additional (unlimited) liability [25]. The option of limiting the representation of a large investor in control and management bodies may also be quite applicable. At the same time, it is possible to provide for the representation in the same bodies of other groups of participants and stakeholders.

\section{Conclusions}

An analysis of the conditions for the functioning of the investment funds allows us to single out several significant conditions that determine the difference in the goals to achieve which the system of regulation, control and decision-making should be oriented on. According to the author, these conditions should include 1) the nature of the investment market (effective or ineffective), as well as 2) the characteristics of the fund's investors (not qualified and qualified). In practice, due to legislative restrictions and economic feasibility, the following combinations of these conditions are possible:

\section{Non-qualified investors - a highly efficient (liquid) market.}

Taking into account the traditional dispersed structure of the investors for this option, the goal of maximum protection of the investors from possible manifestations of opportunism of fund managers (management companies) is quite justified. In other words, in this case, the existing system of control and management of investment funds for unqualified investors is quite justified. As practical recommendations, the following can still be attributed

- strengthening the responsibility of management companies in disclosing the aggregate level of the fund's costs and shifting the attention of ordinary investors to this very indicator when choosing an investment fund;

- reducing the regulatory burden on the companies that provide management of exchange-traded funds - the specifics of the functioning of these funds practically excludes the manifestation of the most dangerous forms of management opportunism.

\section{Qualified investors - a low efficient (non-liquid) market.}

This option, on the contrary, is characterized by a concentrated structure of investors, and it is they who, in most cases, initiated the creation of a fund with the involvement of an external or affiliated management company in the administration of the fund. As a result, the problem of the conflict of interests like "controlling investor - fund management" loses its relevance, but a whole range of other potential conflicts of the controlling investor with the minority investors and other participants in the investment process arises. It is important that the composition of these participants, and hence the content of conflicts, changes depending on the format and investment orientation of the fund (private equity or venture capital fund, hedge fund, etc.). In these conditions, the most expedient is to change the model of control and management of the fund, its transformation into a stakeholder model of corporate governance: 
- $\quad$ highlighting the coordination of significant interests of all the participants in the investment process and the stakeholders as a priority goal;

- providing the regulator with greater freedom in developing internal procedures, regulations, rules and codes that reflect the specifics of the activities of a particular fund, deliberately adopted or even developed by the participants in the investment process, who in this case inevitably have sufficient qualifications.

In addition, measures aimed at offsetting the excessive influence of the controlling investor may be quite reasonable. For example, limiting the representation of a given investor in an investment committee with a simultaneous expansion of the presence of other participants therein, or increasing the responsibility of the controlling investor, up to imposing full responsibility on him, following the example of limited partnerships.

\section{References}

1. S. Bhattacharyya, V. Nanda, Review of finance, 3, 885 (2013)

2. D Del Guercio, E Genc, H Tran, Journal of financial economics, 3, 535 (2018)

3. T. Houge, J. Wellman J. Journal of business ethics, 2, 129 (2005)

4. L. Ma., Y. Tang, J-P. Gomez, Journal of finance, 2, 587 (2019)

5. M. Qian, journal of corporate finance, 1, 45(2011)

6. M.Qian, B.Yu B, Applied economics letters, 12, 967(2015)

7. A.A. Metzger, Bulletin of the Humanitarian University, 2 (2), 36 (2013)

8. Federal Law dated November 29, 2001 No. 156-FL «On Investment Funds»

9. The Civil Code of the Russian Federation (Part One): Federal Law No. 51-FL dated 30.11.1994.

10. The basic corporate governance standard for financial institutions that are brokers, dealers, managers, depositories, registrars (draft), http://www.naufor.ru/

11. Guidelines for members of the board of directors (supervisory board) of a financial institution. Appendix to the letter of the Bank of Russia dated 28.02.2019 No. IN-0628/18, https://cbr.ru/

12. O.I. Shalina, Economics and Management, 6, 99 (2009)

13. A.E. Abramov et al, Economics of investment funds: monograph (2015)

14. I.N. Tkachenko, Analysis of the concepts of assessing the contribution of stakeholders, or On the issue of stakeholder value, New trends in the development of corporate governance and business: materials of the Intern. scientific-practical conf. (Yekaterinburg, November 9, 2017), 93(2017).

15. I.N. Tkachenko, A.A. Zlygostev, Manager, 4,40 (2018)

16. Yu.M. Emohonova, Bulletin of NSUEU, 2, 193 (2017)

17. A.A. Metzger, Bulletin of the Humanitarian University, 1 (1), 64 (2013)

18. Bank of Russia Ordinance No. 4129-Y dated September 5, 2016 "On the composition and structure of assets of joint-stock investment funds and assets of mutual investment funds."

19. L.P. Kharchenko, Problems of modern economics, 3 (39) (2011)

20. D. Bogle, The Guide to a Reasonable Investor. A reliable way to make a profit in the stock market (2013).

21. A.A. Metzger, Bulletin of the Humanitarian University, 1, 15(2018) 
22. G. Kommer Souverän investieren mit Indexfonds \& ETF. Wie Privatanleger das Spiel gegen die Finanzbranche gewinnen (2018)

23. M. Ritzau, Die große Fondslüge. Falsch beraten von Finanztest, Sparkasse, Banken und Co (2016).

24. Yu.M. Ermokhina Interaction of the participants in the investment process with a private equity fund: interests, Bulletin of NSUEU (2017)

25. Hedge-Fonds Marktentwicklung, Risiken und Regulierung, Positionspapier der Eidg. Bankenkommission. September 2007, https://www.finma.ch/

26. The official website of the Bank of Russia, http://cbr.ru

27. The Cbonds Group of Companies, https://investfunds.ru/about/ 